\title{
"O QUE É ISSO CRESCENDO NO MEU BARCO?": UM PROJETO DE DIVULGAÇÃO E EXTENSÃO CIENTÍFICA PARA O ENSINO DE BIOLOGIA MARINHA
}

\section{"WHAT IS GROWING UNDER MY BOAT?": A SCIENTIFIC DIVULGATION AND EXTENSION PROJECT FOR THE MARINE BIOLOGY TEACHING}

\author{
FORTUNATO, Humberto Freitas de Medeiros ${ }^{1}$ \\ VANÇATO, Yollanda Carolina da Silva²
}

\begin{abstract}
ResUMO
Um projeto de Extensão Universitária foi desenvolvido no ano de 2018 com o objetivo de fornecer conhecimento teórico e prático sobre assuntos relacionados à Biologia Marinha. Oito alunos adolescentes da turma de vela Básico Dingue 2 da ONG Projeto Grael, em Jurujuba, Niterói - Rio de Janeiro participaram das atividades teórico-práticas do projeto. Os alunos mostraram seu conhecimento prévio acerca do assunto, desenvolveram um experimento científico de bioincrustação in situ e produziram cartazes para demonstrar o conhecimento adquirido. De forma geral, o projeto foi executado com sucesso, pois teve um retorno positivo do público-alvo. Este projeto pode ser repetido com diferentes públicos e assim esperamos minimizar o distanciamento entre sociedade e Universidade, atingindo principalmente atuais e futuros profissionais do mar, por meio da troca de conhecimento teórico e prático sobre Biologia Marinha.
\end{abstract}

Palavras-chave: Bioincrustação; Divulgação científica; Extensão universitária; Organismos marinhos bentônicos; Projeto Grael.

\section{ABSTRACT}

A University Extension Project was developed in 2018 aiming to provide theoretical and practical knowledge on Marine Biology issues. Eight teenage students from the Basic Dingue sailing boat class from the NGO "Projeto Grael", located in Jurujuba, Niterói in the state of Rio de Janeiro participated in the project's theoretical and practical activitie. The students showed their prior knowledge on the subject, developed a scientific in situ biofouling experiment, and produced posters to demonstrate the acquired knowledge. In general, the project was successful, in that it had a positive return from the target audience. The project can be repeated with different audiences, thus hoping to shorten the distance between society and University. The goal is to reach current and future professionals of the sea by exchanging theoretical and practical knowledge on Marine Biology.

${ }^{1}$ Doutorando em Oceanografia (PPG OCN - UERJ), mestre em Ecologia e Evolução (PPGEE - UERJ) e bacharel em Biologia Marinha (FAMATh). Rio de Janeiro, RJ, Brasil. e-mail: hfmfortunato@gmail.com ${ }^{2}$ Graduada em Ciências Biológicas pela Universidade do Estado do Rio de Janeiro (UERJ). Rio de Janeiro, RJ, Brasil. ORCID: https://orcid.org/0000-0002-5835-2194 . e-mail: yollandaferreira@gmail.com

"O QUE É ISSO CRESCENDO NO MEU BARCO?": UM PROJETO DE DIVULGAÇÃO E EXTENSÃO CIENTÍFICA PARA O ENSINO DE BIOLOGIA MARINHA 
DOI: $10.12957 /$ e-mosaicos.2019.40484

KEYWORDS: Biofouling, Scientific divulgation, University extension, Benthic marine organisms, Grael Project.

\section{INTRODUÇÃO}

Nos últimos anos, a divulgação científica e a extensão universitária vêm ganhando os holofotes dentro das universidades brasileiras. No entanto, muitos acadêmicos e estudantes têm dúvidas sobre o que são e como realizar projetos nessas áreas.

Neste texto, nós abordaremos questões relacionadas à divulgação científica e extensão universitária e mostraremos resultados de um exemplo de projeto de extensão realizado no ano de 2018 que teve como objetivo fornecer conhecimento teórico e prático sobre assuntos relacionados à Biologia Marinha. Por fim, apontaremos aperfeiçoamentos que podem ser feitos para que a troca de conhecimento entre cientistas e sociedade seja ampliada e contínua.

\section{FALANDO DE CIÊNCIA COM A SOCIEDADE}

A divulgação científica é a exposição do conhecimento científico para a esfera social, ou seja, é o diálogo entre o meio científico com toda a sociedade (GRILLO, 2013, 333 f.). Normalmente, a informação científica é levada à sociedade por jornalistas especializados em determinadas áreas, como Economia, Meio Ambiente etc. Os cientistas, por sua vez, deveriam ser os principais difusores deste conhecimento, uma vez que eles produzem o conhecimento científico. Porém, a maioria dos cientistas tem dificuldade de apresentar seus estudos de forma correta e simples para o restante da sociedade (leigos).

A alta quantidade de informação sobre questões tecnológicas, econômicas e ambientais obtida diariamente, principalmente pela mídia digital, pode estar sendo o gatilho para o crescimento da divulgação científica. Assim, pesquisadores de todo o mundo têm buscado aumentar a conexão com o público leigo, por meio de ferramentas on-line, às quais permitem uma comunicação mais simples sem omitir as questões técnicas e filosóficas por trás das grandes perguntas científicas (FAUSTO et al., 2012; LEVY E VILLAVICENCIO, 2017). Espera-se que desta forma, o número de pessoas interessadas e engajadas quanto à ciência cresçam nos próximos anos. Para que a divulgação científica tenha sucesso, é necessário adequar o texto ou apresentação a um público-alvo, ter uma linguagem compreensível e ser objetivo. Um dos maiores divulgadores científicos foi Carl Sagan, astrônomo norte-americano, que conseguia transmitir o conhecimento de física e de cosmologia para os mais diversos grupos sociais. Para isso, o autor utilizava uma linguagem simples, repleta de comparações, inserindo o indivíduo no Universo e expondo suas próprias dúvidas, inclusive sobre a existência de Deus (SAGAN, 2008). Alguns exemplos de pesquisadores brasileiros que realizam divulgação da ciência são a neurocientista Suzana Herculano e o físico/astrônomo Marcelo Gleiser, os quais possuem obras literárias e participam de 
DOI: $10.12957 / \mathrm{e}-m o s a i c o s .2019 .40484$

diversos programas de televisão que convertem traduzir textos científicos em textos compreensíveis para toda a sociedade (HERCULANO-HOUZEL, 2002, 2003, 2005; GLEISER, 2011, 2016; GLEISER e MATUCK, 2016).

\section{DA UNIVERSIDADE PARA AS RUAS}

A carreira acadêmica é baseada no tripé Ensino, Pesquisa e Extensão. O professor tem por obrigação dar aulas, desenvolver o conhecimento científico do país pesquisando e levar a Universidade para fora de seus muros, oferecendo benefícios à sociedade. Sendo assim, a extensão científica é uma articulação indissociável entre ensino e pesquisa (FORPROEX, 1987,18 p.), atuando como via de mão dupla, na qual a Universidade leva um serviço à sociedade que, em contrapartida, retribui com o conhecimento prático, elucidando as necessidades momentâneas da população.

Projetos de extensão ainda são um desafio no Brasil, pois um acadêmico possui uma alta carga de trabalho em ensino e pesquisa e, muitas vezes, marginaliza a extensão. Por outro lado, a extensão pode atuar como uma forma de minimizar o estresse diário, uma vez que nesta área o profissional é obrigado a abandonar o individualismo e deve abraçar o coletivo.

\section{ENSINO DE BIOLOGIA MARINHA POR MEIO DA EXTENSÃO UNIVERSITÁRIA}

Na zona de interface continente-mar, é onde encontramos diversas espécies de animais e vegetais que não possuem capacidade de movimentação e vivem fixados a substratos sólidos, os chamados organismos incrustantes (WAHL, 1989). Apesar de este processo ser natural no ambiente aquático, o excesso de incrustantes em estruturas submarinas pode causar danos às estruturas submersas (Fig. 1), reduzir a velocidade das embarcações, aumentar o consumo de combustível e emissão de gases do efeito estufa, incrementando os gastos econômicos em quase um bilhão de dólares/ano (VIETTI, 2009, p. 36-38). No aspecto ecológico, a bioincrustação em superfícies antrópicas pode facilitar a introdução de espécies invasoras no ambiente marinho (GEWING e SHENKAR, 2017), causando possíveis distúrbios ambientais.

Cerca de $80 \%$ da população mundial vive na região litorânea. O ambiente marinho instiga o conhecimento das pessoas, mas poucos são os projetos de extensão nesta área no Brasil, como o Projeto Coral-Sol (CREED et al., 2017; BRBIO, 2019), o Projeto Ilhas do Rio (ILHAS DO RIO, 2019), Projeto Ecorais (BRBIO, 2019). O projeto "O que é isso crescendo no meu barco?" tem o objetivo de fornecer conhecimento teórico e prático sobre assuntos de biologia marinha para pessoas que trabalham diretamente com o mar. Este projeto pode ser realizado com praticamente qualquer público, desde crianças a adultos que vivem no e do mar, realizando atividades esportivas, navegação ou comercialização de organismos marinhos. 
Figura 1: Barco Fuzzarca do Projeto Grael após três meses submersos sem limpeza

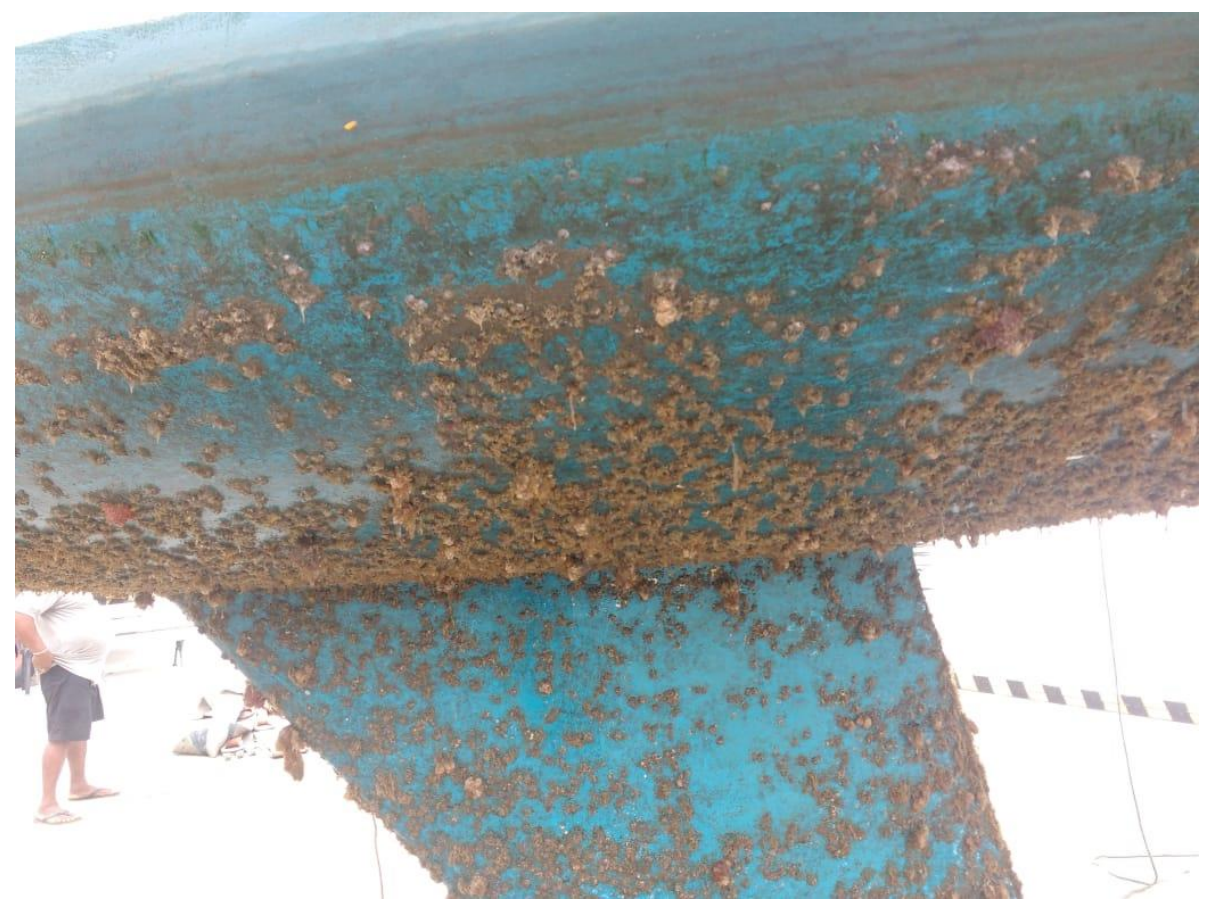

Foto: Projeto Grael

A primeira atividade do projeto de extensão foi realizada em parceria com a ONG Projeto Grael (PG), em Jurujuba, Niterói - RJ. Oito alunos da turma de vela Básico Dingue 2 foram selecionados para participarem das atividades. Os alunos têm idade média de 12 anos e estão iniciando suas atividades marítimas no PG.

O projeto de extensão foi realizado entre os meses de agosto e outubro, com o total de sete encontros de aproximadamente duas horas cada. Durante os encontros, os alunos desenvolveram atividades teóricas e práticas relacionadas à bioincrustação marinha (Fig. 2).

Figura 2. Fluxograma das atividades teórico-práticas realizadas no projeto de extensão

\begin{tabular}{|c|c|c|c|}
\hline $\begin{array}{l}\text { Palestra sobre } \\
\text { bioincrustação }\end{array}$ & $\begin{array}{l}\text { Experimento de } \\
\text { bioincrustação }\end{array}$ & $\begin{array}{l}\text { Observação da } \\
\text { comunidade } \\
\text { incrustante }\end{array}$ & $\begin{array}{c}\text { Confecção de } \\
\text { cartazes }\end{array}$ \\
\hline
\end{tabular}

Fonte: Yollanda Vançato

\section{Metodologia}

1. Palestra inaugural sobre o Projeto

Esta atividade consistiu em uma palestra teórica interativa sobre temas de Biologia Marinha, tais como: bioincrustação, sucessão ecológica, organismos marinhos 
DOI: $10.12957 / \mathrm{e}-m o s a i c o s .2019 .40484$

incrustantes, bioinvasão e poluição marinha (Fig. 3). Também foram discutidos os problemas causados pelos organismos incrustantes nas embarcações e métodos de limpeza dos barcos. Durante a palestra, os alunos foram incentivados a participar por meio de perguntas sobre divulgação científica e os demais temas supracitados. A palestra foi filmada com a finalidade de gravar as respostas dos alunos e, posteriormente, analisar o conhecimento prévio dos alunos sobre os temas abordados.

Figura 3: Palestra inaugural no Projeto Grael, realizada no dia 27/08/2018. Duas turmas participaram desta palestra, a pedido da coordenação do Projeto Grael

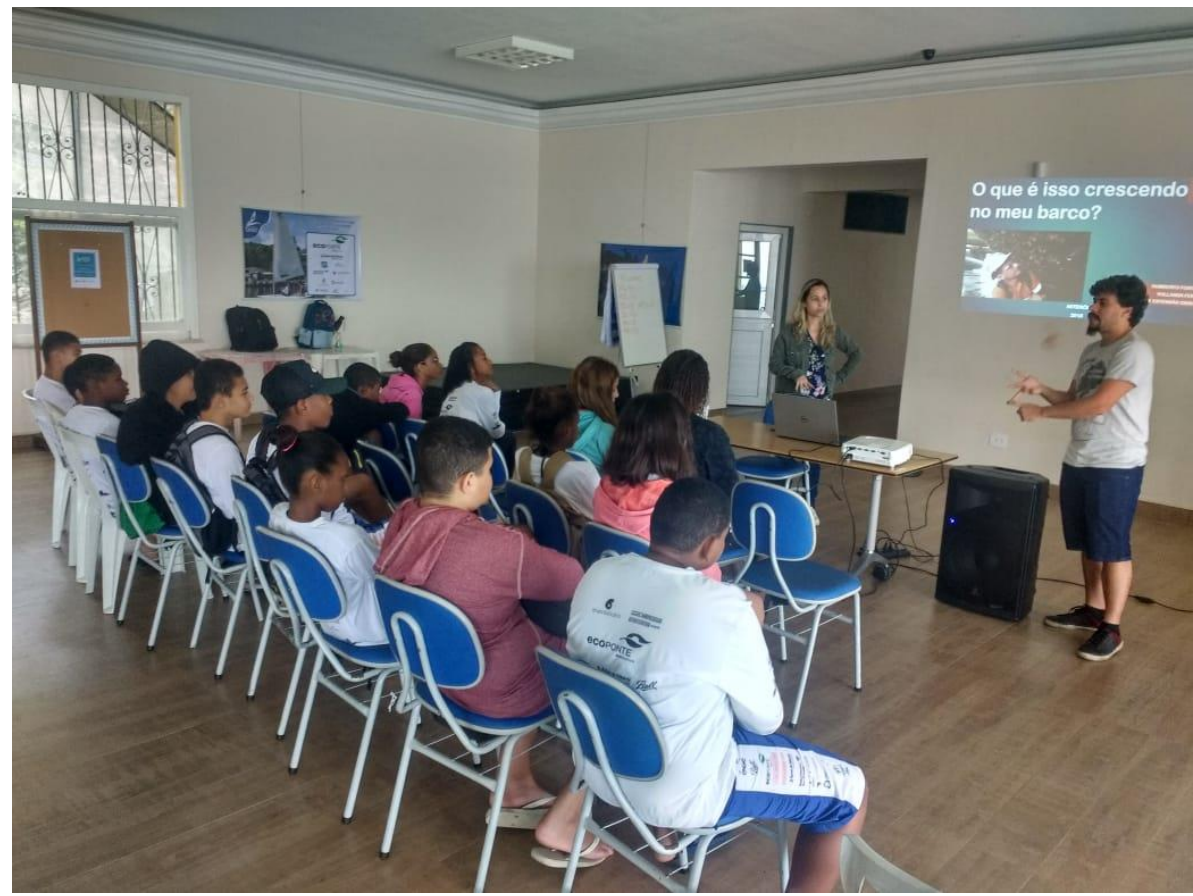

Foto: Projeto Grael

\section{Experimento de bioincrustação}

Uma vez que este projeto teve como objetivo aproximar os alunos de uma turma de náutica com questões de biologia marinha, decidiu-se utilizar materiais de fácil acesso, de baixo custo e do cotidiano destes alunos. Por isso, atividade prática consistiu na realização de um experimento de bioincrustação in situ (Fig.4). Nesta atividade, os alunos teriam que observar o crescimento de organismos marinhos sobre diferentes materiais. Assim, no píer da sede do Projeto Grael, foram fixadas quatro placas de diferentes materiais: fibra, madeira, metal (utilizadas no projeto para a confecção de estruturas náuticas) e plástico (dito, por eles, como o material poluidor 
DOI: $10.12957 / \mathrm{e}-m o s a i c o s .2019 .40484$

mais observado na Baía de Guanabara). Cordas e pesos de chumbo foram adicionados às superfícies e presos ao píer. O acompanhamento do processo de bioincrustação durou 36 dias, nesse tempo, já é possível observar tanto os micro quanto os microorganismos incrustantes (DA GAMA et al., 2002). As placas foram retiradas da água, fotografadas e devolvidas para água, semanalmente para acompanhamento. A quantificação da comunidade incrustante foi realizada por meio da metodologia de pontos aleatórios (MEESE e TOMICH, 1992, p. 59-73), com folha de acetato, amplamente utilizada em estudos quantitativos com invertebrados marinhos. Quando possível, os organismos incrustantes foram identificados por fichas de identificação fornecidas pelos autores.

Figura 4: Realização da atividade prática. A- anotação dos organismos observados nas diferentes placas, B- imagem exemplificando a retirada e imersão das placas na água, C- observação e quantificação das placas

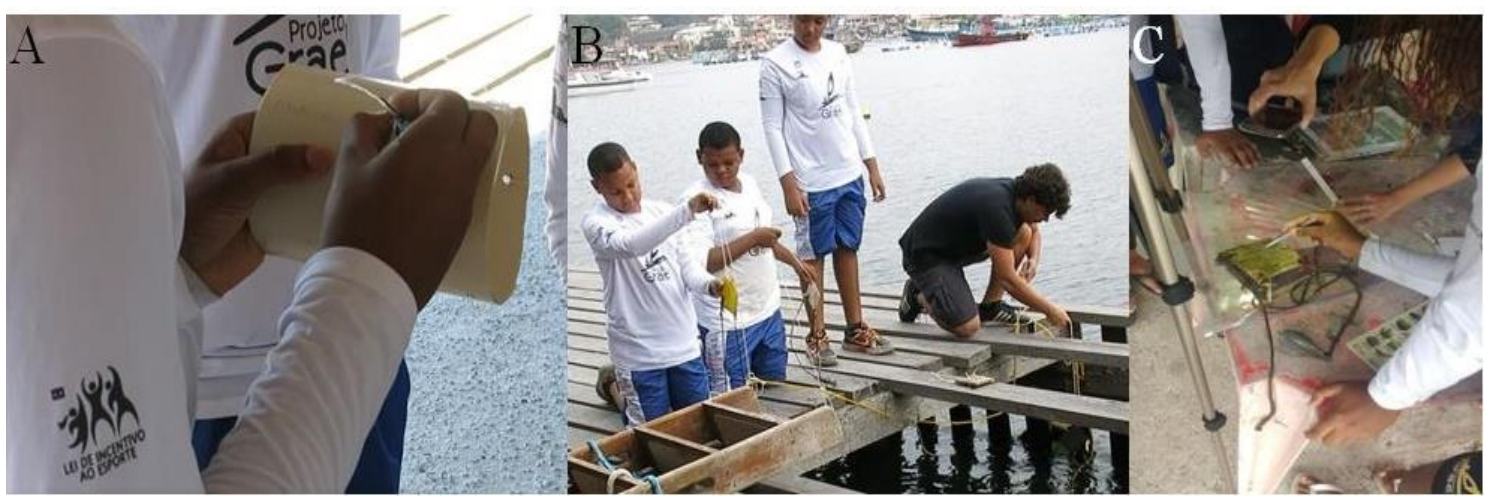

Fotos: Humberto Fortunato

\section{Observação da comunidade incrustante}

Esta atividade consistiu em uma visita guiada a uma plataforma flutuante de propriedade do Projeto Grael. Nesta, os alunos puderam observar a comunidade bentônica em estágio avançado de incrustação (Fig. 5).

\section{Confecção de cartazes}

A atividade de encerramento consistiu na elaboração de cartazes, pelos alunos, sobre os temas abordados durante a atividade de extensão e sobre os resultados do experimento de bioincrustação. Nesta atividade, pode ser avaliado o conhecimento adquirido pelos alunos após a participação no projeto de extensão. 
DOI: $10.12957 /$ e-mosaicos.2019.40484

Figura 5: Alunos da turma Básico Dingue 2 - observando a comunidade bentônica em estágio clímax no flutuante.

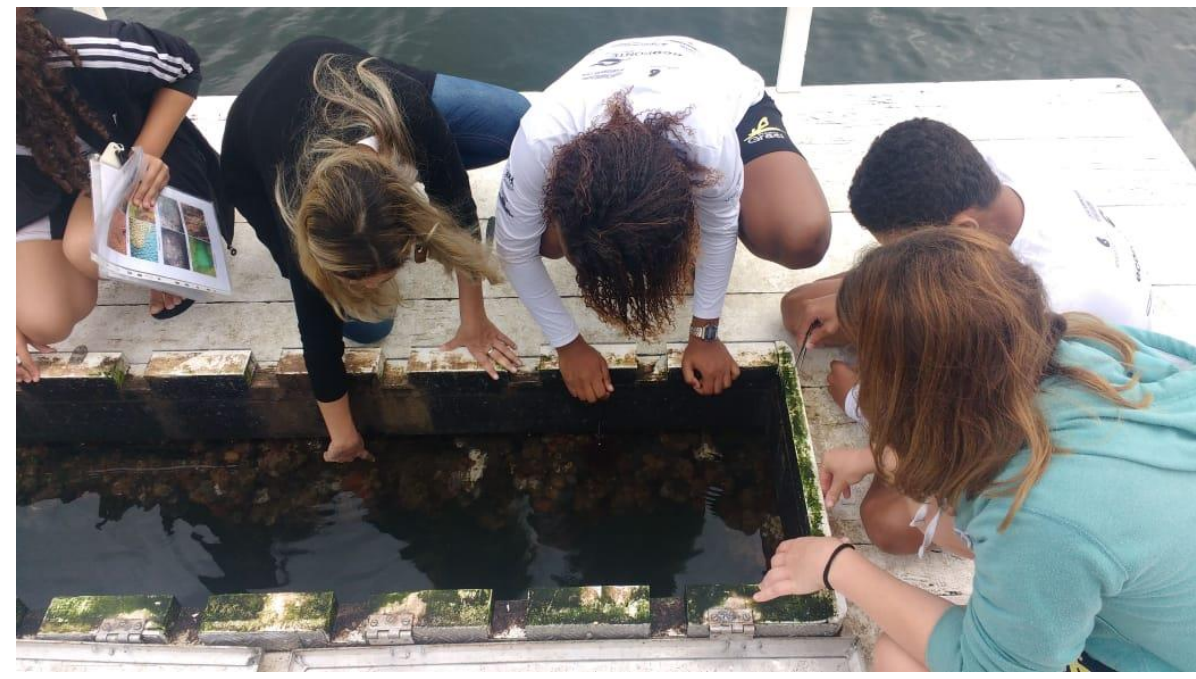

Foto: Projeto Grael

\section{RESULTADOS}

\section{Avaliação e desenvolvimento do conhecimento científico}

Durante a palestra inaugural, diversas perguntas foram feitas aos jovens para avaliar o grau de conhecimento referente à Biologia Marinha. De acordo com as respostas dos alunos, podemos observar que os mesmos não tinham conhecimento algum ou possuíam conhecimento superficial sobre os temas abordados (Quadro 1). Para desenvolver o conhecimento dos alunos, todo o projeto foi voltado para a troca de informação, de forma casual, mas mantendo o rigor da metodologia científica. Desta forma, durante os encontros, perguntas e respostas foram trocadas entre pesquisadores e estudantes.

Quadro 1: Questionamentos e respostas durante a palestra

\begin{tabular}{|l|l|}
\hline \multicolumn{1}{|c|}{ Perguntas } & \multicolumn{1}{c|}{ Respostas } \\
\hline O que é divulgação científica? & $\begin{array}{l}\text { A maior parte dos alunos não respondeu ou informou } \\
\text { que não sabia. }\end{array}$ \\
Para que serve & Nenhuma resposta foi dada. \\
Como fazer? & "Falar para as pessoas." $(*)$ \\
$\begin{array}{l}\text { O que cresce nos cascos dos barcos } \\
\text { dentro do mar? }\end{array}$ & "Craca, marisco, alga." \\
$\begin{array}{l}\text { Alguém discorda? } \\
\text { Qual o nome desse fenômeno? }\end{array}$ & Ninguém discordou. \\
\hline
\end{tabular}

"O QUE É ISSO CRESCENDO NO MEU BARCO?": UM PROJETO DE DIVULGAÇÃO E EXTENSÃO CIENTÍFICA PARA O ENSINO DE BIOLOGIA MARINHA 


\begin{tabular}{|c|c|}
\hline \multicolumn{2}{|l|}{ OI: $10.12957 / \mathrm{e}-m o s a i c o s .2019 .40484$} \\
\hline $\begin{array}{l}\text { Quais são os principais organismos } \\
\text { incrustantes? }\end{array}$ & "Craca e marisco." \\
\hline $\begin{array}{l}\text { Esse processo é natural ou provocado } \\
\text { pelo homem? }\end{array}$ & "Natural." \\
\hline Como a bioincrustação ocorre? & Não souberam responder. \\
\hline Ela causa problema para vocês? & Alguns responderam sim e ou outros não. \\
\hline Quais? & $\begin{array}{l}\text { "A craca corta, o limo faz escorregar, os bichos } \\
\text { deixam o barco pesado" }\end{array}$ \\
\hline Qual é a solução para este problema? & "Lavar, limpar, raspar, jogar veneno." \\
\hline $\begin{array}{l}\text { Qual é o principal tipo de lixo que vocês } \\
\text { observam no mar? }\end{array}$ & "Tem muito lixo, de tudo." \\
\hline $\begin{array}{l}\text { O lixo marinho pode estar associado à } \\
\text { bioincrustação? }\end{array}$ & Não souberam associar. \\
\hline Tem algum animal ou planta nesse lixo? & Responderam sim. \\
\hline $\begin{array}{l}\text { Por que um organismo de outro lugar } \\
\text { pode causar problemas? }\end{array}$ & $\begin{array}{l}\text { "Pode extinguir as espécies que são do lugar. Os } \\
\text { bichos de um lugar podem viver no outro, porque se } \\
\text { eles conseguem viver lá podem viver aqui também." }\end{array}$ \\
\hline
\end{tabular}

Fonte: Elaborado pelos autores. $(*)$ Aspas indicam a exata resposta dada por algum dos alunos.

Com a realização do experimento de bioincrustação por submersão de placas, os alunos acompanharam o processo inicial de incrustação marinha ao longo de 36 dias (Fig. 6). Eles observaram a formação de biofilme, a incrustação por algas, o assentamento de cracas, poliquetas e ascídia. Os alunos concluíram, junto com o auxílio dos autores, que a madeira foi a superfície mais incrustada, a fibra e o plástico tiveram maior riqueza de espécies (algas verdes e calcárias, cracas, ascídia colonial e poliquetos) e o metal foi completamente coberto por filme bacteriano e algas filamentosas. 
DOI: $10.12957 /$ e-mosaicos.2019.40484

Figura 6. Experimento de bioincrustação em placas de diferentes superfícies ao longo de 36 dias de submersão realizado no Projeto Grael

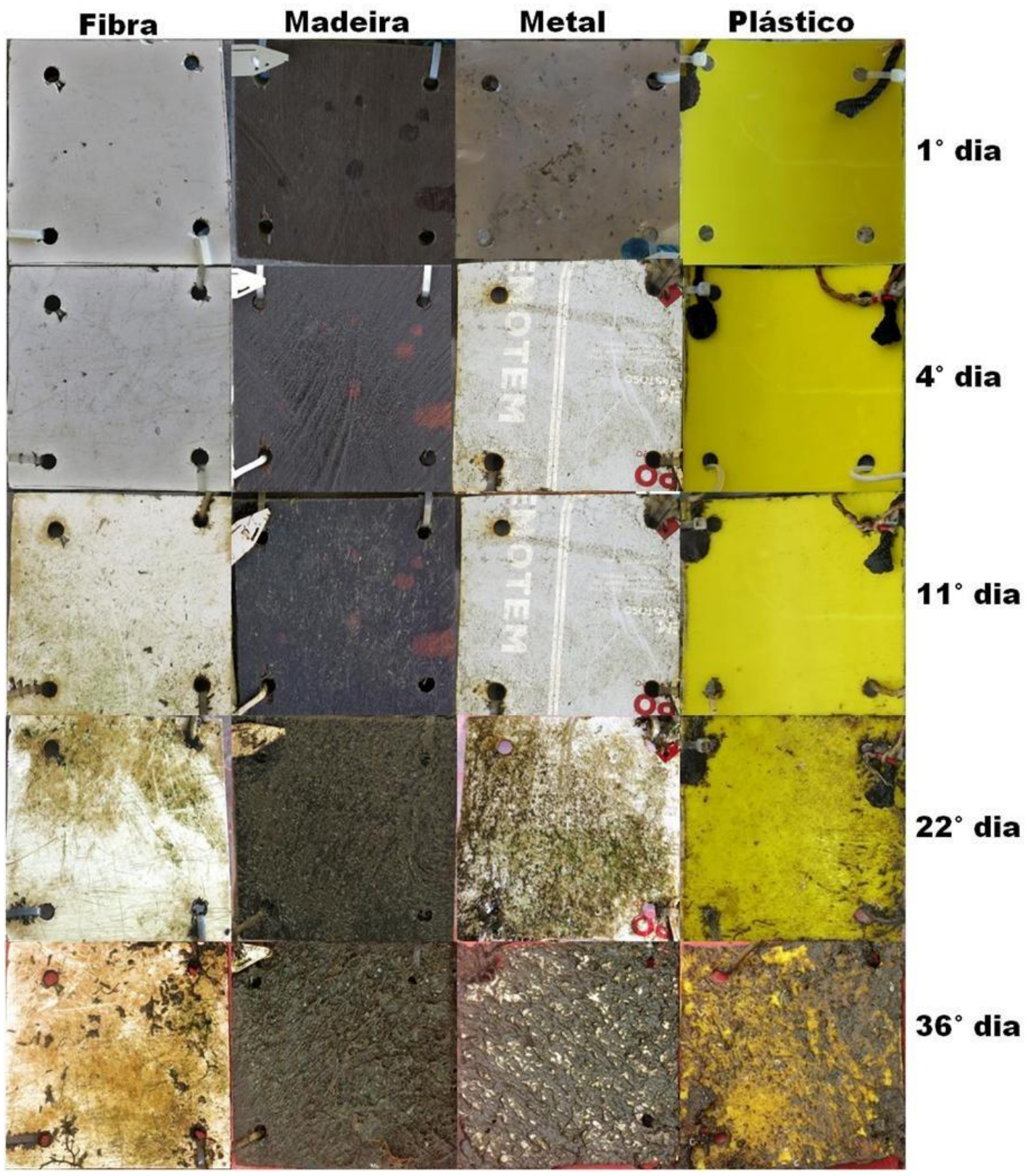

Fotos: Humberto Fortunato.

Para finalizar as atividades do projeto de extensão, os alunos confeccionaram cartazes sobre bioincrustação e o experimento de bioincrustação que realizaram durante dois meses (Fig. 7). Com essa atividade, foi possível avaliar o conhecimento desenvolvido pelos alunos sobre a temática abordada. No cartaz de bioincrustação, os alunos fizeram uma linha do tempo mostrando como ocorre esse processo, utilizando imagens de organismos marinhos como bactérias, diatomáceas, algas, cracas, mexilhões, esponjas e corais. No segundo cartaz, referente ao experimento de 
DOI: $10.12957 / \mathrm{e}-m o s a i c o s .2019 .40484$

bioincrustação, os alunos ilustraram a metodologia de submersão de placas, a avaliação quantitativa da incrustação e a sequência de incrustação das placas. Uma série de figuras foram cedidas pelos autores, mas os alunos escolheram quais entrariam e em qual tema, indicando que aprenderam sobre o tema.

Figura 7: Confecção e finalização do produto realizado pelos alunos da turma de Básico Dingue 2 do Projeto Grael

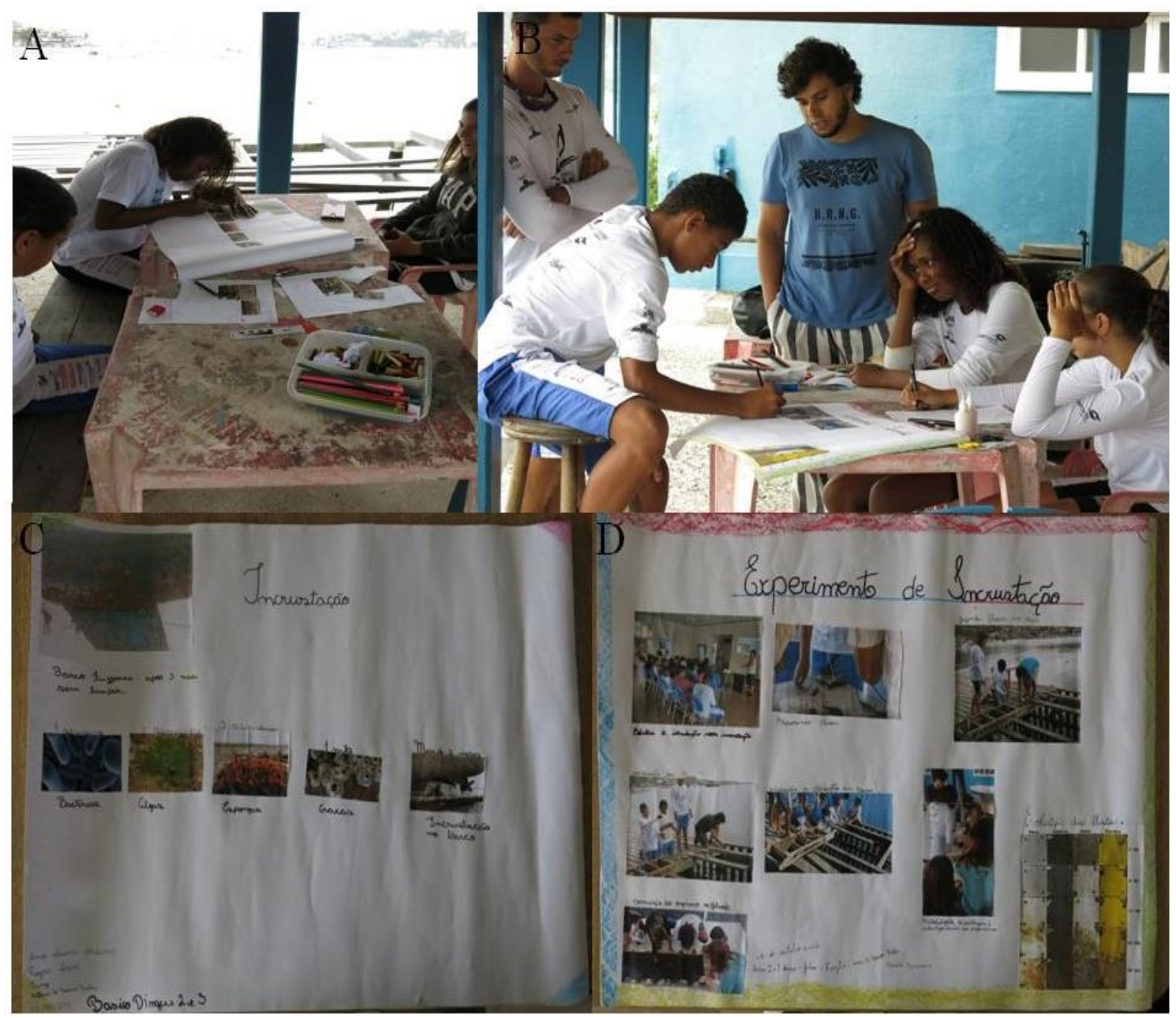

Fotos: Humberto Fortunato.

\section{Ampliando os horizontes}

Após as atividades do projeto "O que é isso crescendo no meu barco?" desenvolvidas no Projeto Grael (PG), os autores foram convidados para ministrar uma oficina teórico-prática na $15^{a}$ Semana Nacional de Ciência e Tecnologia organizada pelo PG. 
DOI: $10.12957 /$ e-mosaicos.2019.40484

O objetivo desta oficina foi informar aos demais profissionais e aos alunos do PG sobre as atividades do projeto de extensão desenvolvido anteriormente e também discutir sobre as temáticas da biologia marinha e bioincrustação.

Inicialmente foi ministrada uma palestra interativa sobre o tema, mostrando as atividades desenvolvidas pelos alunos no projeto de extensão (Fig. 8A). Posteriormente, os participantes observaram os organismos incrustantes na plataforma flutuante e nas placas utilizadas no experimento (ver metodologia), que foram retiradas do mar e observadas em uma lupa (Fig. 8B).

Para finalizar a oficina, foi realizada uma dinâmica de grupo em roda sobre o equilíbrio do ecossistema (Fig. 8C). Com essa dinâmica, os participantes puderam refletir sobre o papel de cada espécie, incluindo o seu papel para o equilíbrio do ambiente.

Além disso, um painel sobre o projeto "O que é isso crescendo no meu barco?" está exposto permanentemente no PG para informar sobre a temática a outras pessoas (Fig.9).

Figura 8: Oficina realizada na $15^{a}$ Semana Nacional de Ciência e Tecnologia. A- palestra sobre o projeto de extensão, B- observação dos organismos incrustantes em lupa, C- dinâmica do equilíbrio no ecossistema.

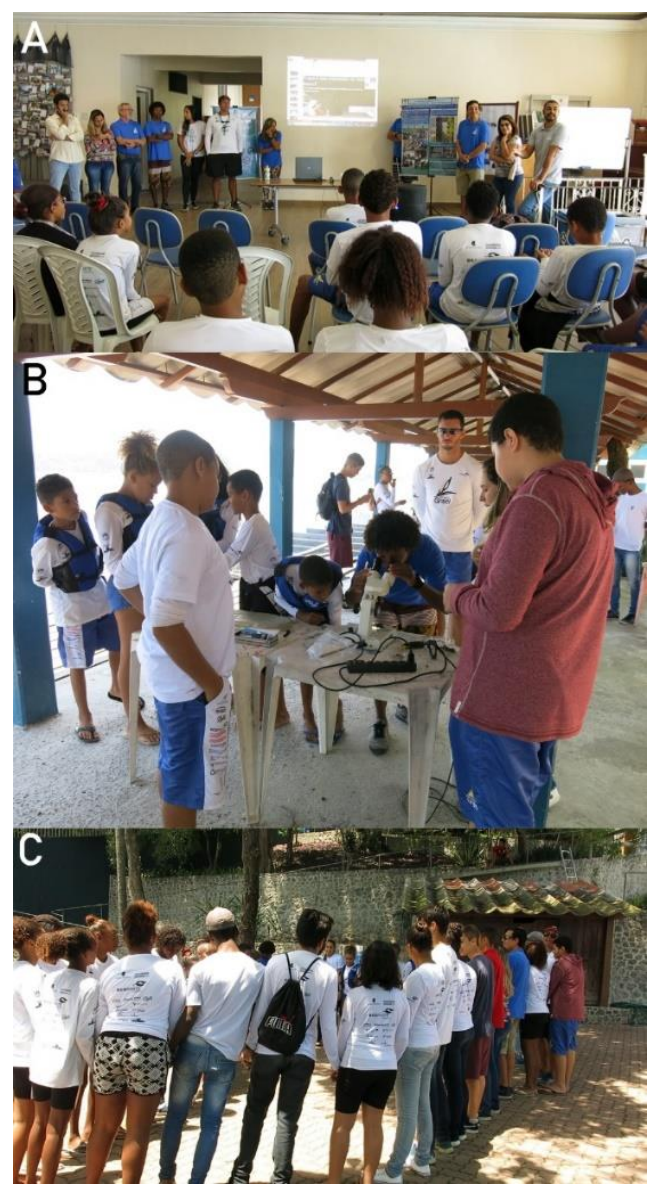

Fotos: Humberto Fortunato 
DOI: $10.12957 / e-m o s a i c o s .2019 .40484$

Figura 9: Pôster do projeto "O que é isso crescendo no meu barco?", confeccionado a partir da parceria dos idealizadores do projeto com a coordenação do Projeto Grael

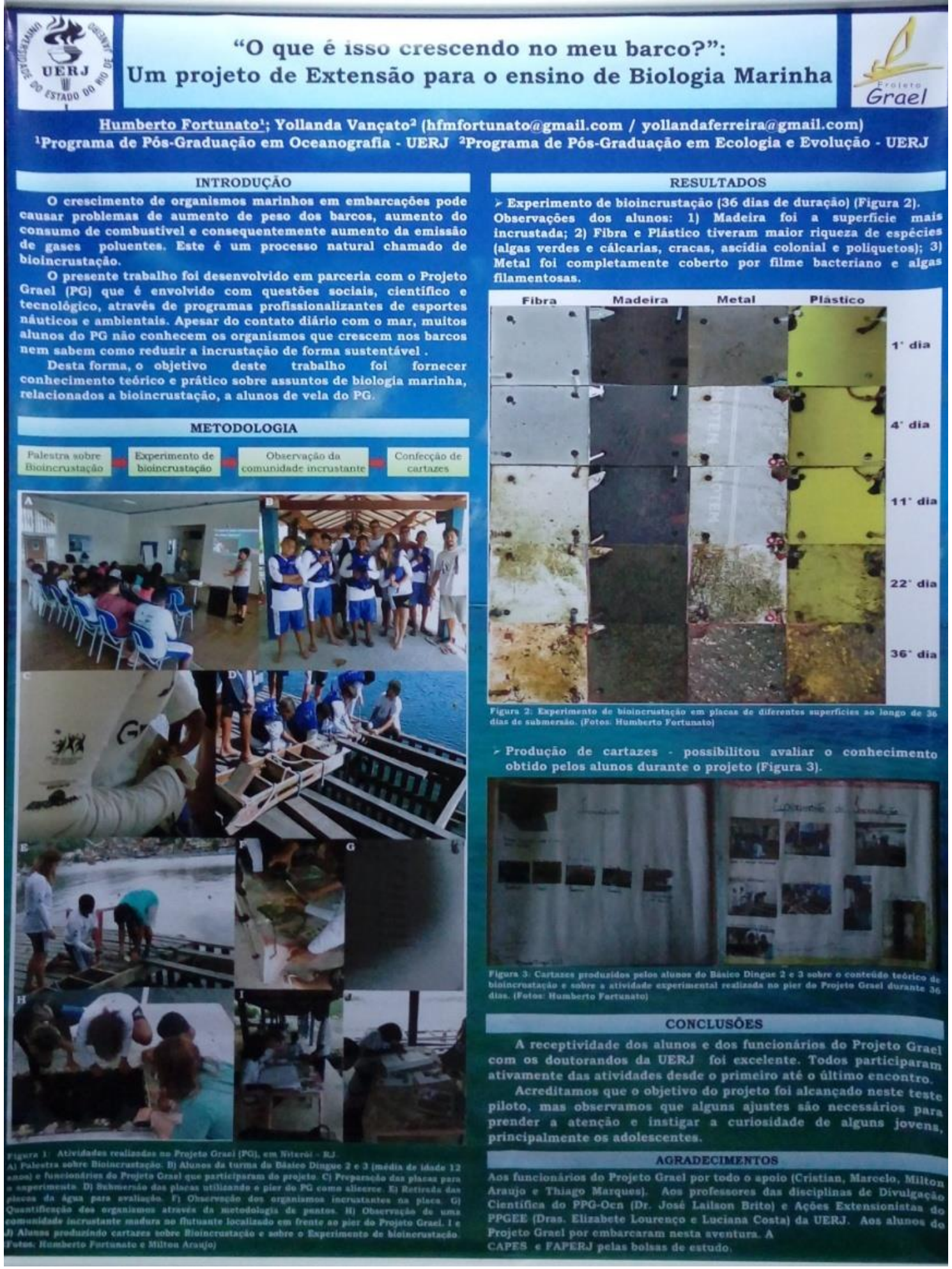

Fotos: Humberto Fortunato

"O QUE É ISSO CRESCENDO NO MEU BARCO?": UM PROJETO DE DIVULGAÇÃO E EXTENSÃO CIENTÍFICA PARA O ENSINO DE BIOLOGIA MARINHA 


\section{CONCLUSÃo}

Este projeto pode ser levado como um exemplo de Divulgação Científica e Extensão Universitária para o ensino Biologia Marinha no Brasil. Acreditamos que conseguimos levar conhecimento científico de forma teórica e prática para os jovens praticantes de atividades náuticas, e os integrantes do Projeto Grael foram apresentados à novas metodologias para a preservação e limpeza de suas embarcações, diminuindo o impacto no ambiente aquático.

Os pesquisadores foram bem recebidos pelos alunos para o desenvolvimento do projeto, entretanto, modificações, quanto à dinâmica das atividades, terão que ser feitas para deter a atenção de todos os participantes por maior tempo.

Sendo assim, com a realização do Projeto "O que é isso crescendo no meu barco?", esperamos minimizar o distanciamento entre sociedade e Universidade, atingindo principalmente atuais e futuros profissionais do mar, por meio de troca de conhecimento teórico e prático sobre as Ciências do Mar.

AgRAdeCimentos: Aos alunos do Projeto Grael por embarcarem nesta aventura. Aos funcionários do Projeto Grael por todo o apoio e incentivo (Cristian, Marcelo, Milton Araújo e Thiago Marques). Aos professores das disciplinas de Divulgação Científica do PPG-Ocn (Dr. José Lailson Brito) e Ações Extensionistas do PPGEE (Dras. Elizabete Lourenço e Luciana Costa) da UERJ. O presente trabalho foi realizado com apoio da Coordenação de Aperfeiçoamento de Pessoal de Nível Superior - Brasil (CAPES) Código de Financiamento 001 e pela Fundação de Amparo à Pesquisa do Estado do Rio de Janeiro (FAPERJ), por meio de bolsas de estudos de nível Doutorado para os autores deste trabalho.

\section{REFERÊNCIAS}

BRBIO. Instituto Brasileiro de Biodiversidade. Disponível em: <http://www.brbio.org.br>. Acessado em: 15 abr. 2019.

CREED, J.C.; OLIVEIRA, A.J.R, FLEURY, B.G.; MANTELATTO, M.C.; OIGMANPSZCZOL, S.S. The Sun-Coral Project: the first social-environmental initiative to manage the biological invasion of Tubastraea spp. In: Brazil. Management of Biological Invasions (8) 2: 2017. p. 181-195.

DA GAMA, BAP; PEREIRA, R.C;CARVALHO,A.G.V.; COUTINHO, R.; YONESHIGUEVALENTIN, Y. The effects of seaweed secondary metabolites on biofouling. Biofouling, 18, 2002. p. 13-20. 
DOI: $10.12957 / \mathrm{e}-\mathrm{mosaicos} .2019 .40484$

FAUSTO, S.; MACHADO, F.A.; BENTO, L.F.J.; IAMARINO, A.; NAHAS, T.R.;MUNGER, D.S. Research Blogging: Indexing and Registering the Change in Science 2.0. PLOS ONE 10(4): e0124184, 2012. Disponível em:

https://doi.org/10.1371/journal.pone.0124184

GEWING, M.T; SHENKAR, N. Monitoring the magnitude of marine vessel infestation by non-indigenous ascidians in the Mediterranean. Marine Pollution Bulletin 121. p. 52-59 doi: 10.1016/j.marpolbul.2017.05.041

GLEISER, M. O fim da terra e do céu: o apocalipse na ciência e na religião. São Paulo: Companhia das Letras, 2011.

GLEISER, M. A simples beleza do inesperado: um filósofo natural em busca de trutas e do sentido da vida. Rio de Janeiro: Record, 2016. 196p.

GLEISER, M.; MATUCK, C.A dança do universo: dos mitos de Criação ao Big Bang. São Paulo: Companhia das Letras, 1997.

GRILLO, S.V.C. Divulgação científica: linguagens, esferas e gêneros. Tese apresentada à Faculdade de Filosofia, Letras e Ciências Humanas como requisito parcial para obtenção do título de livre-docente. São Paulo: Universidade de São Paulo, 2012.

HERCULANO-HOUZEL S.O Cérebro Nosso de Cada Dia. Rio de Janeiro, Vieira \& Lent, 2002.

HERCULANO-HOUZEL, S. Sexo, Drogas, Rock' $n^{\prime}$ Roll e Chocolate. O Cérebro e os Prazeres da Vida Cotidiana. Rio de Janeiro, Vieira \& Lent, 2003.

HERCULANO-HOUZEL, S.O Cérebro em transformação. Rio de Janeiro, Objetiva, 2005.

ILHAS DO RIO (2019) Projeto Ilhas do Rio. Disponível em: <http://ilhasdorio.org.br/>. Acesso em: 15abr 2019.

LEVY, D.; VILLAVICENCIO, A. Web-based tools to increase public understanding of nuclear technology and food irradiation. International Journal of Social, Behavioral, Educational, Economic, Business and Industrial Engineering 11. 2017. p. 70-74.

MEESE, R.J.; TOMICH, P.A. Dots on the rocks: a comparison of percent cover estimation methods. Journal of Experimental Marine Biology and Ecology 165. 2002. p. 59-73.

SAGAN, C. Variedades da experiência científica - Uma visão pessoal da busca por Deus. São Paulo, Companhia das Letras, 2006. 
DOI: $10.12957 / \mathrm{e}-\mathrm{mosaicos} .2019 .40484$

VIETTI,P. New hull coatings for Navy ships cut fuel use, protect environment. Office of Naval Research Corporate Strategic Communications. In: The Navy's environmental magazine Current's. Fall 2009. p. 36-38.

WAHL, M. Marine epibiosis. I. Fouling and antifouling: some basic aspects. Marine Ecology Progress Series 58, 1989. p.175-189

I FORPROEX - Encontro de Pró-reitores de Extensão das Universidades Públicas Brasileiras. Conceito de extensão, institucionalização e financiamento. Brasília, 1987.

Recebido em 26 de fevereiro de 2019.

Aceito em 16 de maio de 2019.

\footnotetext{
(c) (7) (-) A e-Mosaicos Revista Multidisciplinar de Ensino, Pesquisa, Extensão e Cultura do Instituto de Aplicação Fernando Rodrigues da Silveira (CAp-UERJ) está licenciada com uma Licença Creative Commons - Atribuição-NãoComercial 4.0 Internacional.

Os direitos autorais de todos os trabalhos publicados na revista pertencem ao(s) seu(s) autor(es) e coautor(es), com o direito de primeira publicação cedido à e-Mosaicos.

Os artigos publicados são de acesso público, de uso gratuito, com atribuição de autoria obrigatória, para aplicações de finalidade educacional e não-comercial, de acordo com o modelo de licenciamento Creative Commons adotado pela revista.
} 